\title{
Methodology for predicting the resistance of North American plants in the Astana Botanical Garden
}

\author{
Gulnara Sitpayeva, Inga Babai ${ }^{*}$ Nikolai Zverev, Velta Massalova, Svetlana Nabieva, Irina \\ Khussainova, and Ainagul Ishaeva
}

RSE "Institute of botany and phytointroduction", Introduction Department, 050040 Almaty, Kazakhstan

\begin{abstract}
The analysis and selection of modern methods of introduction prediction was carried out to create a promising list of woody plants of the North America site in the Astana Botanical Garden in Nur-Sultan. Using a system-arealogical approach and interpolation forecasting, botanical nurseries were selected - they are donors of generative and planting material to be included in the collection. 33 taxa or $45 \%$ of plants corresponding to winter hardiness in the natural area of the climatic zone of Nur-Sultan were selected using the method of climatic analogues of Mayer and winter hardiness zones. The methodology we chose allowed us to expand by $55 \%$ the list of plants that have higher winter hardiness in the cultivated area than in the natural one. A promising list of 80 taxa from 19 families and 34 genera has been compiled.
\end{abstract}

\section{Introduction}

The aim of the work was the selection of a methodology for predicting the stability of introduced plants and the development of promising lists of woody plants to create an exposition titled "North America" in the territory of the State Botanical Garden in the city of Nur-Sultan.

The introduction of woody plants in Kazakhstan has been performed for a relatively short period. The first experience of landscaping of cities in Kazakhstan was noted in the 19th and early 20th centuries, during the construction of military outposts of Tsarist Russia in the middle of the XIX century. The settlements of Sofia (now Talgar), Nadezhdinskoye (Issyk) and Zailiysky (Almaty) were founded. Work in this focal area made it possible to select sustainable woody plants for landscaping settlements in the South-East of Kazakhstan. Moreover, the list of woody plants totaled only 24 taxa [1]. The development of industry and agriculture of the Republic in the twentieth century required a new scale of landscaping, a scientific approach to the selection of plant range. For the first time, scientific and systemic approaches to plant introduction in Kazakhstan were laid with the establishment of a network of botanical gardens in the early twentieth century.

\footnotetext{
* Corresponding author: babaiv1102@gmail.ru
} 
Botanical gardens serve as the scientific bases for testing and introducing new plants into landscaping and green construction. Until recently, five botanical gardens, such as the Mangyshlak Experimental Botanical Garden (Aktau), Zhezkazgan Botanical Garden (Zhezkazgan), Altai Botanical Garden (Ridder), Ili Botanical Garden (Bakanas settlement, Almaty Region) and the Main Botanical Garden (Almaty) made it possible to draw up scientifically based "Ranges of plants for landscaping various regions of Kazakhstan" [2-7]. The existing network of botanical gardens and arboreal -nurseries in Kazakhstan covers the South-East, North-East, Central, Southern and Western regions. Due to the large area of the Republic in the meridian-based and latitude-based directions and the great ecological diversity of natural and climatic conditions, the existing network of botanical gardens did not cover the climatic conditions of the North of Kazakhstan.

This problem did not allow us to give accurate forecasts of the stability of plants introduced in the landscaping of settlements in the northern regions. The need to create an introduction nursery in this region was one of the pre-requisites for the opening of the Astana State Botanical Garden in the city of Nur-Sultan. In this case, the main objectives was to compile promising lists of dendrological collections. The diversity of the dendrological flora of North America and its wide scattering in latitude and longitude allows for a large selection of species for introduction from areas close to the climatic conditions of the city of Nur-Sultan.

To form a collection of woody plants "North America" the matter arose which was related to the selection of a sustainable range. The problem posed was solved by the following tasks: 1. Selection of a methodology for predicting plant resistance. 2. Analysis of the introduction experience of North American woody plants in existing domestic botanical gardens and nurseries, as well as botanical gardens of neighboring countries. 3 . Drawing up a prospective list of plants of the North America site for the Nur-Sultan Botanical Garden.

\section{Materials and methods}

The objects of research were the arboreal plants of the North American flora and the results of their introduction in Kazakhstan [2-7] and in Siberia [8]. An analysis of the climatic regimes of the geographical points of Kazakhstan and Siberia was carried out using the Scientific and Applied Reference on Climate of the USSR [9] and the work of T.N. Vstotskaya et al. [8]. The forecast of cold resistance was performed according to the winter hardiness zones of Rehder [10] and the forecasting method of cold resistance [11]. The taxonomic affiliation of plants was specified according to A. Raeder [9] and the electronic database of plants Tropicos [12]. To develop promising lists of woody plants of the North America site, a system-arealogical approach was used [11] and interpolation forecasting [13].The phenological monitoring of plants at the points of introduction of Kazakhstan were performed according to the accepted methodology [14]. Winter hardiness was estimated in spring according to the Lapin-Sidneva system [15] in accordance with the following indicators: no damage in winter - winter hardiness corresponds to 1 point, freezing of the tips of annual shoots -2 points, freezing of the annual growth -3 points, freezing out of older shoots -4 points, freezing the trunk to the level of snow cover -5 points, freezing the plant to the root neck -6 points, 7 points - the complete death of the plant.

\section{Research results and discussion}

Initially, the method of climatic analogues developed by H. Mayer [16-17] was the basis for establishing a collection of live plants of the botanical gardens of Kazakhstan. The main 
principle in this method was the selection of plants with close climatic characteristics of areas of natural growth with the point of introduction tests. Then, when selecting promising plants for introduction, the method of climatic analogues, developed by A. Roeder, was used. He introduced the division of plants into winter hardiness zones according to the average long-term annual minimums of air temperature in the natural area. The temperature boundaries of the zones A. Rehder [9] are: Zone 1 - below $-50{ }^{\circ} \mathrm{C}$; Zone 2 - from -50 to $35^{\circ} \mathrm{C}$; Zone 3 from -35 to $-20^{\circ} \mathrm{C}$; Zone $4-$ from -20 to $-10{ }^{\circ} \mathrm{C}$; Zone 5 - from -10 to -5 ${ }^{\circ} \mathrm{C}$; Zone 6 - from -5 to $+5{ }^{\circ} \mathrm{C}$; Zone 7 - from +5 to $+10{ }^{\circ} \mathrm{C}$.

In such a forecast, the main indicator of the stability of introducers is considered to be the correspondence or close indicators in the new point of introduction of annual temperature minimums to those in the natural range. The winter hardiness of plants in their natural range should also correspond to their resistance at the point of introduction with similar annual temperature minimums. The experience of plant introduction in Almaty using this one-component approach showed that this method gives positive results of introduction only in 40\%-76.4\% [18-20]. Research experience shows that in the arid climate of Almaty, plant resistance is affected not only by winter temperature drop, but also by low air humidity in summer, lack of soil moisture, spring return frosts and other environmental factors. A previous analysis of meteorological data indicates that Kazakhstan has no environmental and climatic analogues with centers of origin of the global dendroflora.

Similar data were obtained by analyzing the results of the introduction of about 1000 species of woody plants in Siberia [21], where the forecast reliability using the method of climatic analogues was 75\%. Later, I.O. Baitulin, M.A. Proskuryakov and S.V. Chekalin [13] proposed a systemic-ecological approach in predicting the stability of introducers. This method involves taking into account many environmental factors of existing points of introduction with further interpolation and extrapolation introduction prediction for the new center of introduction tests. Moreover, for a new introduction nursery, a range is already selected that is well adapted to close environmental conditions. in nearby and intermediate nurseries. However, the experience of introduction shows that often plants in the culture have higher winter hardiness than in the natural range. For example, a stable species in Almaty, Mahonia aquifolium (Pursh) Nutt. according to Rehder [10], in nature it belongs to zone 5 (with a minimum temperature index of -10 to $-5{ }^{\circ} \mathrm{C}$ ), and the average annual minimum in Almaty is $25^{\circ} \mathrm{C}$, with an absolute long-term minimum of $37.7{ }^{\circ} \mathrm{C}$, which corresponds to 3 winter hardiness zones. These studies are confirmed by the work of B.N. Golovkina [22] on the cold tolerance of plants in natural and cultured habitats.

Studies have shown that out of 497 analyzed Eurasian species, $306(61.5 \%)$ have greater cold tolerance in the cultivated area than in the natural area. Numerous facts of such adaptation subsequently led to new theoretical developments and made it possible to expand the approach to predicting the stability of introduced species, taking into account their extreme cold resistance in the cultured area [10]: The authors developed a systemarealogical introduction forecast. The features of this forecast make it possible to take into account the positive experience of plant introduction in points where their cold resistance is higher than in the natural habitat. It is natural to assume that the prognosis for plants can be both positive (when the cold tolerance of plants under artificial or natural conditions corresponds to a new introduction site), and negative (the cold tolerance of plants in a natural or cultivated area does not correspond to a new introduction point).

However, a negative introduction forecast does not completely exclude the species from the long-term list, and often when testing plants it becomes erroneous. I.O. Baitulin et al. [12] indicated that "... positive prediction in introductions gives 3.5 times fewer errors than it does when deciding to prohibit the introduction of a species". In order to verify and clarify this position, the list was compiled for plants with both a positive and a negative 
introduction forecast. To compile a prospective list, a forecast of plant resistance was carried out using the following key [11].

1. Identification according to published data of the minimum average long-term annual minimum temperature in the natural and cultured area.

2. The species corresponds in its cold hardiness in the natural habitat to the point of introduction at which the introduction forecast is made (category of positive forecast A).

2.1. The species does not correspond in its cold hardiness in the natural habitat to the introduction point for which the forecast is being made. The tension of cold stresses at the point of introduction is greater than that characteristic of the species in the natural range.

3. The species corresponds in extreme cold hardiness in the cultivated area to the point of introduction for which an introduction forecast is being made (positive prognosis category B).

3.1 The species does not correspond to the extreme cold hardiness in the cultivated area of the introduction point for which the forecast is being made - a negative introduction forecast.

With the help of such forecasting, it is possible to expand the composition of promising species and increase the reliability of forecasting on the cold tolerance of plants.

In systemic-arealogical forecasting, the first step is to identify the specific nature of the climate of the new introduction site and the climatic features of the existing dendrological nurservies.

There were 13 dendrological research stations in Kazakhstan at different times. Some of these are now functioning as botanical gardens in Almaty, Bakanas, Zhezkazgan, Ridder, Aktau. And 3 research stations in Shymkent, Turkestan and Schuchinsk have changed their work profile. Dendrological stations in Balkhash, Zhairem, Karaganda, Ekibastuz and Atyrau were permanently shut down.

From the analysis of climate data from above stations it is obvious that the duration of the frost-free period of Nur-Sultan is 124 days with an annual minimum of air temperature of $38{ }^{\circ} \mathrm{C}$, an annual maximum of air temperature $+36^{\circ} \mathrm{C}$, with an accumulation of the sum of positive temperatures for the year $2600^{\circ} \mathrm{C}$. The annual precipitation in our forecast did not matter, since artificial watering is planned in the botanical garden. Climatic conditions of the botanical gardens of the cities of Zhezkazgan, Ridder and Karaganda are closest in terms of cold resistance and other selected parameters to the predicted nursery. At these points of introduction, experience has been gained on the resistance of woody plants of the global flora, including North America. On the other hand, experience has been gained in the cultivation of introduced plants in the botanical gardens of neighboring countries with close climatic conditions -

these are the botanical gardens of Siberia [8].

Analysis of the climatic characteristics of the siberian introduction centers revealed that the closest indicators to the city of Nur-Sultan (Astana) are Novosibirsk, Omsk, Barnaul, and Tomsk. These centers became supportive in the analysis of cold tolerance of North American wood introducers in the cultivated area. The climate of the analyzed region belongs to the second winter hardiness zone of A. Rehder [10]. To identify promising North American plants introduced in Siberian gardens, we selected woody plants with high winter hardiness of 1-2 points, or plants with lower winter hardiness, but capable of quickly recovering and entering the phase of generative propagation after winter damage.

When selecting plants, in addition to winter hardiness, factors in relation to moisture, soil, and drought tolerance of introduced species in botanical nurseries were taken into account. As a result of this work, a prospective list of 80 taxa of woody plants belonging to 19 families and 34 genera, 60 species and 20 forms (cultivars) of the flora of North America was compiled. All plants have full or satisfactory ( 2 points) winter hardiness. According to the winter hardiness zones of A. Rehder [10], the selected species are 
distributed as follows: 2 species, or $3.3 \%$, belong to zone 1; the second zone includes 25 species $(41.6 \%)$; to the 3 rd zone -14 species (23.3\%); to the 4th zone -15 species $(25 \%)$; to the 5th zone -4 species $(6.6 \%)$. It is obvious that the winter hardiness of plants in the cultivated area from 3.4 and 5 zones is higher than in the natural one. Using the method of climatic analogues and the method of winter hardiness A. Rehder allowed us to choose only plants from zones 1 and 2, which amounted to 27 taxa or only $45 \%$ of the total list. The application of the interpolation forecast and the system-arealogical approach expanded the prospective list by 33 species (55\%) and 20 forms. It is natural to assume that cultivars of the species Picea pungens Engelm., Thuja occidentalis L, Prunus virginiana (L.) Mill. do not have a natural range and their stability can be determined only by direct testing in new conditions.

For verification the accuracy of our prediction, some species presented in the list were selected according to a negative introduction forecast and have low winter hardiness in the cultivated area. The work in this area will continue.

Another positive aspect of our methodology for predicting plant resistance is the identification of points of introduction - donors of planting and genetic material to establish a collection site.

The compiled prospective list provides a preliminary forecast for winter hardiness, and a final assessment of the resistance of plants will be revealed by their direct test in the Astana Botanical Garden.

\section{Conclusions}

Our theoretical and practical analysis, the approaches we have chosen made it possible to conduct a preliminary forecast of the stability of introducers and make a promising list of woody plants of the North American flora to create a collection site in the Astana Botanical Garden in Nur-Sultan. The prospective list consists of 19 families, 34 genera of 60 species and 20 forms (cultivars).

Using the method of climatic analogues of Mayer and A. Rehder, twenty seven taxa or $45 \%$ of the total number of plants were attracted. The application of the interpolation forecast and the system-arealogical approach made it possible to expand the list by more than $50 \%$ (33 species) by plants resistant in the cultivated area that grow in warmer areas in the natural habitat. In addition, the prospective list contains 20 forms or cultivars of the species Picea pungens Engelm., Thuja occidentalis L, Prunus virginiana (L.) Mill., which underwent successful adaptation in the botanical gardens of Kazakhstan and Siberia with similar climatic conditions.

Analysis of climatic data and interpolation forecasting made it possible to identify promising donor areas for attracting planting and generative material to the Astana Botanical Garden. These include introduction centers in the cities of Ridder, Zhezkazgan, Novosibirsk, Barnaul, Omsk, Tomsk. Our methodology for compiling a prospective list will allow us to attract species that are previously stable in the conditions of the city of Nur-Sultan, which will reduce the time of testing and the number of potential introduction errors.

Acknowledgments. This work was performed within the framework of grant funding on the topic: AR05133161 "Academic support for the establishment of the State Botanical Garden in Astana: development of long-term lists of collection funds of woody plants and mobilization of reproduction material for their establishment", program 217 "Development of science", subprogram 102 "Grant financing of academic research", priority:"Life and health science".

We express our gratitude in establishing an introduction nursery to employees of the Arboretum of KazNIIILH LLP in Schuchinsk, North Kazakhstan Region, for obtaining seedlings and sowing materials of expedition trips. 
We remain grateful to the staff of the RSE Altai Botanical Garden of the Ministry of Education and Science of the Republic of Kazakhstan, Ridder, for their assisting in collecting generative and planting material for establishing a collection of woody plants in the Astana Botanical Garden.

\section{References}

1. S. G. Sarsenova, J. K. Botanova, Parks and squares of the city of Almaty 1868-1916: collection of archival documents and materials (Oner, Almaty, 2005)

2. The range of ornamental plants for landscaping settlements of the Southern Balkhash Area (Academy of Science of the Kazakh SSR, Alma-Ata, 1978)

3. The range of ornamental plants for landscaping industrial centers of the Karaganda region (Academy of Science of the Kazakh SSR, Alma-Ata, 1978)

4. A range of ornamental plants for landscaping the Dzhezkazgan industrial region (Academy of Science of the Kazakh SSR, Alma-Ata, 1979)

5. Range of ornamental plants for landscaping Almaty (Academy of Science of the Kazakh SSR, Alma-Ata, 1979)

6. An range of ornamental plants for landscaping cities and villages of East Kazakhstan (Academy of Science of the Kazakh SSR, Alma-Ata, 1981)

7. G. T. Sitpayeva, S. V. Chekalin, et al. Range and catalog of woody plants recommended for landscaping the city of Almaty (Almaty, 2017)

8. T. N. Vstotskaya, I. Y. Koropachinsky, T. I. Kiseleva, A. B. Gorbunov, A. V. Karakulov, N. P. Lapteva, Introduction of woody plants in Siberia (Novosibirsk, 2017)

9. Scientific-applied reference on the climate of the USSR, Series 3. Perennial data. Vol. 18. Book 2. (Leningrad, 1989)

10. A. Rehder, Manual of cultivated trees and shrubs hardy in North America (New York, 1949)

11. S. V. Chekalin, G. T. Sitpayeva, V. A. Massalova, Resettlement and cold tolerance of woody plants of Eurasia (subtropical, temperate and subpolar territories), Vol. 1 (Almaty, 2012)

12. Tropicos.org. Missouri Botanical Garden Available at: https://www.tropicos.org/home/. Last check on 17.10. 2019

13. I. O. Baitulin, M. A. Proskuryakov, S. V. Chekalin, A systematic and ecological approach to plant introduction in Kazakhstan (Alma-Ata, 1992)

14. Methodologies of introduction studies in Kazakhstan (Alma-Ata, 1987)

15. P. I. Lapin, S. V. Sidneva, Experience in introducing woody plants (Moscow, 1974)

16. H. Mayer, Die Waldungen von Nord America (Munchen, 1890)

17. H. Mayer, Walbau dur naturgeschichtlicher jrundlage (Berlin, 1909)

18. V. G. Rubanik, Introduction of gymnosperms in Kazakhstan (Alma-Ata, 1974)

19. V. G. Rubanik, T. A. Zheronkina, Introduction of trees and shrubs of Europe in Kazakhstan (Alma-Ata, 1980)

20. V. G. Rubanik, I. N. Soloninova, Introduction of North American woody plants in Southeast Kazakhstan (Academy of Science of the Kazakh SSR, Alma-Ata, 1989)

21. T. N. Vstovskaya, Abstracts of the All-Union Conference on the theoretical basis of plant introduction (Moscow, 1981)

22. B. N. Golovkin, Cultivation area of plants (Moscow, 1988) 